Asian J. Med. Biol. Res. 2019, 5 (3), 180-185; doi: 10.3329/ajmbr.v5i3.43585

\author{
Asian Journal of \\ Medical and Biological Research \\ ISSN 2411-4472 (Print) 2412-5571 (Online) \\ www.ebupress.com/journal/ajmbr
}

\title{
Article \\ Prevalence of obesity and dietary habits of university students: a cross-sectional study
}

Md. Sabbir Ahmed ${ }^{1 *}$, Kanij Fatima Anee ${ }^{1}$, Mohammad Tazrian Abid $^{2}$, Md. Oashkuruni Hridoy², Al-Riaj Hasan $^{2}$, Moriom Tuz Marufa ${ }^{2}$, Tamanna Hassan ${ }^{2}$ and Sunjida Munmun ${ }^{2}$

${ }^{1}$ Department of Community Health and Hygiene, Patuakhali Science and Technology University, Dumki, Patuakhali-8602, Bangladesh

${ }^{2}$ Faculty of Nutrition and Food Science, Patuakhali Science and Technology University, Dumki, Patuakhali8602, Bangladesh

*Corresponding author: Md. Sabbir Ahmed, Department of Community Health and Hygiene, Patuakhali Science and Technology University, Dumki, Patuakhali-8602, Bangladesh. Phone: +8801727930083; E-mail: sabbir.nfs@gmail.com

Received: 17 July 2019/Accepted: 19 August 2019/ Published: 30 September 2019

\begin{abstract}
The objectives of this study was to assess the prevalence of overweight and obesity in a sample of students from the Patuakhali Science and Technology University, Bangladesh and examine their usual eating habits. A cross-sectional survey of 260 students $(65.38 \%$ male and $34.62 \%$ female) aged $20.81 \pm 1.63$ were chosen randomly from the Patuakhali Science and Technology University campus during May to July 2019. Students were asked to fill out a self-reported questionnaire that included questions on their eating, drinking and smoking habits. Also, their weight, height and body mass index were measured. Body mass index (BMI) was used to assess students' weight status. Statistical analyses were performed using the SPSS software (version 23.0). Results shows that, majority of the students (67.3\%) were of normal weight. Based on BMI classification, the prevalence of overweight was more common among the male students compared to females (23.5\% vs. $10 \%)$. In contrast, prevalence of obesity was more common among female students (3.3\% vs. 2.9\%). A significant difference in BMI was observed between male and female students ( $p<0.01)$. The majority of the students $(70.4 \%)$ reported that they took meals regularly. In terms of breakfast intake, less than half of the students $(44.6 \%)$ reported that they took their breakfast daily. There was a significant gender difference in the frequency of snacks intake apart from regular meal $(\mathrm{p}<0.05)$. Female students were more prone to snacks consumption compared with male students. The unhealthy eating habits of the students was indicated by the fact that near about half of the students (46\%) reported eating fried food daily or three to four times per week. Soft drinks consumption among the students were significantly associated with gender ( $\mathrm{p}<0.05)$. The present results suggest the necessity of nutrition and health promotion programs for university students, especially programs emphasizing weight management.
\end{abstract}

Keywords: obesity; dietary habits; university students

\section{Introduction}

Worldwide, the prevalence of overweigh and obesity is increasing day by day in both developed and developing countries as well as in Bangladesh (Hu, 2008). In the last 20 years the prevalence of obesity in developing countries increased by three times due to urbanization with increased consumption of high calorie foods and sedentary lifestyle (Hu, 2008; Popkin et al., 2012). Studies among university students in developing countries show high prevalence of overweight and obesity: Africa (Nigeria: 10\%; Egypt: 25.3\%-59.4\%, South Africa: 10.8\%-24\%; Asia (Bangladesh: 20.8\%; China: 2.9\%-14.3\%; Malaysia: 20\%-30.1\%, Thailand: 31\%, Pakistan: 13\%-52.6\%, and India: 11\%-37.5\%; Latin America (Colombia: 12.4\%-16.7\%; Mexico: 31.6\%, the Middle and 
Near East (Saudi females: 47.9\%, Oman: 28.2\%; Kuwait: 42\%, Iran 12.4\%, and Turkey: 10\%-47.4\%) (Peltzer et al., 2014).

Popkin BM and his colleagues identified some risk factors in their review paper, those are associated with overweight and obesity among university students or (young) adults: (1) socio-demographic factors (mainly male gender, older age and higher socioeconomic status; (2) Social factors: lack of social support, capital and lack of religiousness; (3) Dietary behavior: intakes of fiber, consumption of red meat, skip breakfast more often, high number of meals, snacking behavior; and (4) Health risk behavior: Physical inactivity, frequent alcohol use, and smoking; (5) Mental health and childhood abuse: poor mental health (depression, anxiety) and childhood physical abuse, sexual and verbal abuse (Pengpid and Peltzer, 2014).

University students represent the youthful age population of a community, and are prone to unhealthy eating habits and foods which might affect their wellbeing and increase the risk of obesity as well as other noncommunicable diseases; like fast food consumption, lower vegetable and/or fruit intake along with physical inactivity and increasing computer and Television viewing hours (Al-Rethaiaa et al., 2010; Al-Qahtani, 2016). Dietary habits of university students usually depend on lecture schedules attended by students and availability of food inside or near to the university campus. It was reported that due to the expansion in the fast-food market and lack of appropriate food courts, students usually face meal skipping, inadequate variety of foods, and unhealthy snacking (Gazibara et al., 2013; Genena and Salama, 2017).

Universities may contribute significantly in reducing the prevalence of obesity among this young population through the promotion of healthy life styles and eating habits. Universities may provide an ideal forum for reaching out to a large number of young adults through nutrition education programs that may positively influence students' eating habits by advocating for the adoption of healthy food choices (Yahia et al., 2008). However, a few study have been conducted among the university students in Bangladesh to assess their nutritional status and dietary pattern. This study is therefore helpful to provide the baseline data for the prevalence of overweight and obesity and the eating habits of Bangladeshi university students. The objectives of this study was to assess the prevalence of overweight and obesity in a sample of students from the Patuakhali Science and Technology University, Bangladesh and examine their usual eating habits.

\section{Materials and Methods}

\subsection{Study design and sample}

A cross-sectional survey was conducted at Patuakhali Science and technology University (PSTU) campus during May to July 2019. A sample of 264 students was calculated based on the estimated prevalence of obesity among Bangladeshi university students (Peltzer et al., 2014) (21\%,CI: 95\%, margin of error $5.0 \%$ and 10\% nonresponse rate). Major inclusion criteria for this study was currently enrolled full time students of the university. Students were selected by simple random sampling technique from each of the faculty. Students' number was determined by probability proportional to size (PPS) technique. Students were unwilling to participate were excluded from the study.

\subsection{Data collection}

Data were collected in two steps. The first step was to fill out the questionnaire and the second step was to perform the anthropometric measurements. Recruited students were asked to fill out a questionnaire related to their eating, drinking and smoking habits. The questionnaire was adopted from a previously published study where authors have standardized its use among university students (Sakamaki et al., 2005; Yahia et al., 2008). Prior to data collection participants were informed about the objectives of the study and they were also instructed how to fill out the questionnaire. After filling out the questionnaire, anthropometric measurements (height and weight) were done by trained research assistants following standardized protocols (Lee and Nieman, 1993). Standing height was measured to the nearest $0.1 \mathrm{~cm}$ without shoes by using a measuring tape. Portable digital (Camry, Model: EB9062) weight scales were used to measure the weight of the respondent with light cloths and bare foot. The scales were checked for accuracy and calibrated every day before data collection. Weights were recorded to the nearest $0.1 \mathrm{~kg}$. Body mass index (BMI) was used to assess students' nutritional status. According to guidelines stated by the National Institutes of Health, weight status was classified into four categories: underweight (BMI $\leq 18.5$ ), normal weight (BMI between $18.5-24.9$ ), overweight (BMI between 25-29.9), and obese (BMI $\geq 30)$ (Yahia et al., 2008).

\subsection{Data analysis}

Statistical analyses were performed using the Statistical Package for Social Sciences (version 23.0, SPSS, Inc.) software. Results were expressed as means \pm SD (standard deviation). Parametric variables were analyzed using 
student's $t$-test, while chi-squared analyses were conducted for non-parametric variables. All reported $P$ values were made on the basis of 2 -sided tests considered statistically significant at $\mathrm{P}<0.05$.

\subsection{Ethics}

All study procedures were carried out following the guidelines of the Helsinki Declaration. Informed consent was obtained from participants prior to participating in the study. Anonymity and confidentiality of data were ensured, and all participants were provided with information about the right to withdraw their data at any time.

\section{Results}

\subsection{Characteristics of the participants}

A total of 260 university students were participated in this study. Characteristics of the participants are described in Table 1. Mean ( \pm SD) age of the students was $20.81 \pm 1.63$ and majority respondents were male $(65.38 \%)$. The average weight of the students were $61.72 \pm 11.39 \mathrm{~kg}$, while the average height was $165.27 \pm$ $8.05 \mathrm{~cm}$. The mean BMI of the participants was $22.52 \pm 3.39$. There was a significant difference between male and female group based on their BMI $(\mathrm{p}<0.001)$.

\subsection{Student's weight status based on BMI category}

Table 2 illustrate that majority of the students $(67.3 \%)$ were of normal weight $(66.5 \%$ of the male students compared to $68.9 \%$ of the female students). Overall the prevalence of overweight and obesity among the students were $18.8 \%$ and $3.1 \%$ respectively. Based on BMI classification, the prevalence of overweight was more common among the male students compared to females $(23.5 \%$ vs. $10 \%)$. In contrast, prevalence of obesity was more common among female students (3.3\% vs. $2.9 \%)$. A significant difference in BMI was observed between male and female students $(\mathrm{p}<0.01)$.

\subsection{Dietary habits of the students}

Table 3 shows the results of questions related to dietary practices with special reference to eating habits, meal patterns, consumption of fruits and vegetables, consumption of fried foods, smoking status etc. The majority of the students (70.4\%) reported that they took meals regularly. In terms of breakfast intake, less than half of the students $(44.6 \%)$ reported that they took their breakfast daily where the percentages of male compared with females were about same. There was a significant gender difference in the frequency of snacks intake apart from regular meal $(\mathrm{p}<0.05)$. Female students were more prone to snacks consumption compared with male students. Daily intake of colored vegetables and fruits were less common among the students $(27.3 \%$ and $8.8 \%$ respectively) with no gender differences. The unhealthy eating habits of the students was indicated by the fact that near about half of the students (46\%) reported eating fried food daily or three to four times per week. Eating daily with friends and family was less common among students $(28.8 \%)$ with no differences in gender. Soft drinks consumption among the students were significantly associated with gender ( $p<0.05)$. Smoking among the students was not common among students. $65 \%$ of the students reported that they never smoked, $10 \%$ were ex-smoker and $25 \%$ were current smokers, which was significantly associated with sex of the respondent $(\mathrm{p}$ $<0.001)$.

Table 1. Characteristics of the study participants.

\begin{tabular}{lllll}
\hline & Total & Male & Female & p value \\
\hline Variables & $\mathrm{n}=260$ & $\mathrm{n}=170$ & $\mathrm{n}=90$ & 0.830 \\
\hline Age $(\mathrm{y})$ & $20.81 \pm 1.63$ & $20.82 \pm 1.55$ & $20.78 \pm 1.77$ & 0.000 \\
Weight $(\mathrm{kg})$ & $61.72 \pm 11.39$ & $65.98 \pm 10.33$ & $53.65 \pm 8.64$ & 0.000 \\
Height $(\mathrm{cm})$ & $165.27 \pm 8.05$ & $168.92 \pm 5.77$ & $158.39 \pm 7.24$ & 0.000 \\
BMI $\left(\mathrm{kg} / \mathrm{m}^{2}\right)$ & $22.52 \pm 3.39$ & $23.09 \pm 3.19$ & $21.42 \pm 3.49$ & \\
\hline
\end{tabular}

Data are presented as mean \pm SD. $p$ value obtained from independent sample t-test. 
Asian J. Med. Biol. Res. 2019, 5 (3)

Table 2. Prevalence of overweight and obesity among students based on BMI by gender.

\begin{tabular}{llllll}
\hline Classification & BMI & Total n (\%) & Male n (\%) & Female n (\%) & p-value \\
\hline Underweight & $\leq 18.5$ & $28(10.8)$ & $12(7.1)$ & $16(17.8)$ & \\
Normal & $18.5-24.9$ & $175(67.3)$ & $113(66.5)$ & $62(68.9)$ & $0.007^{* *}$ \\
Overweight & $25-29.9$ & $49(18.8)$ & $40(23.5)$ & $9(10.0)$ & \\
Obese & $\geq 30$ & $8(3.1)$ & $5(2.9)$ & $3(3.3)$ & \\
\hline
\end{tabular}

$* *$ significant at $\mathrm{p}<0.01$

Table 3. Dietary habits of the students.

\begin{tabular}{|c|c|c|c|c|c|}
\hline & & Total & Male & Female & \\
\hline Question & Level & $n(\%)$ & $n(\%)$ & $n(\%)$ & $p$-value \\
\hline $\begin{array}{l}\text { Do you take your meals } \\
\text { regularly? }\end{array}$ & $\begin{array}{l}\text { Always regular } \\
\text { Irregular }\end{array}$ & $\begin{array}{l}183(70.4) \\
77(29.6)\end{array}$ & $\begin{array}{l}116(68.2) \\
54(31.8)\end{array}$ & $\begin{array}{l}67(74.4) \\
23(25.6) \\
\end{array}$ & .297 \\
\hline Do you take breakfast? & $\begin{array}{l}\text { Daily } \\
\text { Three or four times per week } \\
\text { Once or twice per week } \\
\text { rarely }\end{array}$ & $\begin{array}{l}116(44.6) \\
99(38.1) \\
21(8.1) \\
24(9.2)\end{array}$ & $\begin{array}{l}76(44.7) \\
66(38.8) \\
13(7.6) \\
15(8.8)\end{array}$ & $\begin{array}{l}40(44.4) \\
33(36.7) \\
8(8.9) \\
9(10.0)\end{array}$ & .965 \\
\hline $\begin{array}{l}\text { How many times do you eat } \\
\text { regular meals except snacks? }\end{array}$ & $\begin{array}{l}\text { One time } \\
\text { Two times } \\
\text { Three times } \\
\text { Four times }\end{array}$ & $\begin{array}{l}60(23.1) \\
126(48.5) \\
67(25.8) \\
7(2.7)\end{array}$ & $\begin{array}{l}33(19.40) \\
91(53.5) \\
43(25.3) \\
3(1.8)\end{array}$ & $\begin{array}{l}27(30.0) \\
35(38.9) \\
24(26.7) \\
4(1.4)\end{array}$ & .070 \\
\hline $\begin{array}{l}\text { How often do you take snacks } \\
\text { apart from regular meals? }\end{array}$ & $\begin{array}{l}\text { Daily } \\
\text { Three or four times per week } \\
\text { Once or twice per week } \\
\text { rarely }\end{array}$ & $\begin{array}{l}82(31.5) \\
89(34.2) \\
43(16.5) \\
46(17.7)\end{array}$ & $\begin{array}{l}46(27.1) \\
54(31.8) \\
34(20.0) \\
36(21.2)\end{array}$ & $\begin{array}{l}36(40.0) \\
35(38.9) \\
9(10.0) \\
10(11.1)\end{array}$ & $.012^{*}$ \\
\hline $\begin{array}{l}\text { How often do you eat green, red } \\
\text { or yellow colored vegetables? }\end{array}$ & $\begin{array}{l}\text { Daily } \\
\text { Three or four times per week } \\
\text { Once or twice per week } \\
\text { rarely }\end{array}$ & $\begin{array}{l}71(27.3) \\
115(44.2) \\
36(13.8) \\
38(14.6)\end{array}$ & $\begin{array}{l}46(27.1) \\
76(44.7) \\
20(11.8) \\
28(16.5)\end{array}$ & $\begin{array}{l}25(27.8) \\
39(43.3) \\
16(17.8) \\
10(11.1)\end{array}$ & .435 \\
\hline How often do you eat fruits? & $\begin{array}{l}\text { Daily } \\
\text { Three or four times per week } \\
\text { Once or twice per week } \\
\text { rarely }\end{array}$ & $\begin{array}{l}23(8.8) \\
39(15.0) \\
82(31.5) \\
116(44.6)\end{array}$ & $\begin{array}{l}13(7.6) \\
22(12.9) \\
51(30.0) \\
84(49.4)\end{array}$ & $\begin{array}{l}10(11.1) \\
17(18.9) \\
31(34.4) \\
32(35.6)\end{array}$ & .166 \\
\hline $\begin{array}{l}\text { How often do you eat fried } \\
\text { food? }\end{array}$ & $\begin{array}{l}\text { Daily } \\
\text { Three or four times per week } \\
\text { Once or twice per week } \\
\text { rarely }\end{array}$ & $\begin{array}{l}44(16.9) \\
76(29.2) \\
54(20.8) \\
86(33.1)\end{array}$ & $\begin{array}{l}28(16.5) \\
48(28.2) \\
38(22.4) \\
56(32.9)\end{array}$ & $\begin{array}{l}16(17.8) \\
28(31.1) \\
16(17.8) \\
30(33.3)\end{array}$ & .844 \\
\hline $\begin{array}{l}\text { How often do you eat with } \\
\text { friends and family? }\end{array}$ & $\begin{array}{l}\text { Daily } \\
\text { Three or four times per week } \\
\text { Once or twice per week } \\
\text { rarely }\end{array}$ & $\begin{array}{l}75(28.8) \\
61(23.5) \\
56(21.5) \\
68(26.2) \\
\end{array}$ & $\begin{array}{l}53(31.2) \\
37(21.8) \\
34(20.0) \\
46(27.1)\end{array}$ & $\begin{array}{l}22(24.4) \\
24(26.7) \\
22(24.4) \\
22(24.4)\end{array}$ & .528 \\
\hline $\begin{array}{l}\text { How often do you drink soft } \\
\text { drinks? }\end{array}$ & $\begin{array}{l}\text { Daily } \\
\text { Three or four times per week } \\
\text { Once or twice per week } \\
\text { rarely }\end{array}$ & $\begin{array}{l}50(19.2) \\
78(30.0) \\
82(31.5) \\
50(19.2)\end{array}$ & $\begin{array}{l}40(23.5) \\
43(25.3) \\
57(33.5) \\
30(17.6)\end{array}$ & $\begin{array}{l}10(11.1) \\
35(38.9) \\
25(27.8) \\
20(22.2)\end{array}$ & $.022 *$ \\
\hline $\begin{array}{l}\text { What type of food do you think } \\
\text { you should eat to have a } \\
\text { balanced nutrition? }\end{array}$ & $\begin{array}{l}\text { Mainly meat } \\
\text { Mainly vegetables } \\
\text { Meat, vegetables and other } \\
\text { variety of foods } \\
\text { others }\end{array}$ & $\begin{array}{l}29(11.2) \\
35(13.5) \\
188(72.3) \\
8(3.1)\end{array}$ & $\begin{array}{l}22(12.9) \\
23(13.5) \\
117(68.8) \\
8(4.7)\end{array}$ & $\begin{array}{l}7(7.8) \\
12(13.3) \\
71(78.9) \\
0(0.0)\end{array}$ & .091 \\
\hline $\begin{array}{l}\text { Please state your smoking } \\
\text { history }\end{array}$ & $\begin{array}{l}\text { Current smoker } \\
\text { Ex-smoker } \\
\text { Never smoke }\end{array}$ & $\begin{array}{l}65(25.0) \\
26(10.0) \\
169(65.0)\end{array}$ & $\begin{array}{l}59(34.7) \\
24(14.1) \\
87(51.2)\end{array}$ & $\begin{array}{l}6(6.7) \\
2(2.2) \\
82(91.1)\end{array}$ & $.000^{* * * *}$ \\
\hline
\end{tabular}

\footnotetext{
* significant at $\mathrm{p}<0.05, * *$ significant at $\mathrm{p}<0.001$
} 


\section{Discussion}

The purpose of this study was to assess the prevalence of overweight and obesity and to figure out the dietary habits in a sample of Patuakhali Science and Technology University students. Body mass index was used to assess weight status. Based on BMI classification of weight status, findings of this study indicate that the majority of students were of normal weight. Normal weight was more prevalent among female students (68.9\%) compared with the male students $(66.5 \%)$ whereas, the prevalence of overweight was more common the male students. Obesity was more common among female students than males in the studied population. A total of $3.3 \%$ of the females were obese compared to $2.9 \%$ of the males. The lower rate of obesity among male students is expected since males are more active in physical activities rather than females. Females are more cautious about their weight status than males, due to society perceptions which encourage females to be slender. This assumption was supported by the fact that only $7.1 \%$ of males were underweight as compared to $17.8 \%$ of females in this studied sample. Obviously, pictures of movie stars and models in fashion magazines and mass media have a strong impact on girls' body shape and image perception (Field et al., 1999; Yahia et al., 2008). University girls see the shape and weight of fashion models as the ideal body shape and figure to attain. Girls with such strong body weight perception can be at risk of developing eating disorders (Taylor et al., 1998). In some recent studies, it was found that prevalence of obesity was more common among the male students in comparison with females (Bertsias et al., 2003; Arroyo et al., 2006). In a study conducted among 749 students (68\% females and 32\% males) recruited from the State University of the Basque Country, prevalence rate of overweight and obesity was $25 \%$ in males compared to $13.9 \%$ in females (Arroyo et al., 2006). Another study conducted among 989 medical students (527 men, 462 women) from the University of Crete reported that approximately $40 \%$ male students and $23 \%$ female students had BMI $>25 \mathrm{~kg} / \mathrm{m}^{2}$ (Bertsias et al., 2003). High prevalence rate of overweight and obesity was also reported in a study conducted in Kuwait University among 842 students (Al-Isa, 1999), at 32\% and 8.9\%, respectively. In the United Arab Emirates, a cross-sectional survey conducted among 300 male students reported that the prevalence rate of obesity was $35.7 \%$ in males and this figure was higher than the rate in females (Musaiger et al., 2003). In terms of eating habits, university students usually do not follow healthy eating habits. The typical university student diet is high in fat and low in fruits and vegetables (Glore et al., 1993). Students often select fast food due to its palatability, availability and convenience. A previous survey by the American Dietetic Association indicated that obesity, or being severely overweight, is a fast-food related issue (Yahia et al., 2008). The Healthy people 2010 objectives include a focus on nutrition and obesity prevention (Yahia et al., 2008). In our study, data analyses of students' eating habits revealed that the majority of students eat meals regularly and eat breakfast daily or three to four times per week. $48.5 \%$ of the students eat meals two times per day. There was a significant gender difference in the frequency of snacks intake apart from regular meal $(\mathrm{p}<0.05)$. Female students were more prone to snacks consumption compared with male students. Daily intake of colored vegetables and fruits were less common among the students (27.3\% and $8.8 \%$ respectively) with no gender differences. The unhealthy eating habits of the students was indicated by the fact that near about half of the students $(46 \%)$ reported eating fried food daily or three to four times per week. The majority of students believe that eating meat, vegetables and other foods will provide them with a balanced diet. About $69 \%$ male students and $79 \%$ female students in this study agreed that it is important to eat a variety of foods to have a balanced and nutritious diet. A study conducted at Midwestern University among 105 male and 181 female students, reported that $94.4 \%$ of the students agreed that it is important to eat a variety of foods for good health (Davy et al., 2006). In another study, healthful diet was classified as a diet that included more fruits and vegetables, and less fat (Wardle et al., 2004). Improving students' knowledge about nutrition and healthy eating habits may promote healthy body weight management among students and reduce the prevalence of overweight and obesity (Yahia et al., 2008). Smoking among the students was not common among students. $65 \%$ of the students reported that they never smoked, $10 \%$ were exsmoker and $25 \%$ were current smokers, which was significantly associated with sex of the respondent ( $\mathrm{p}$ $<0.001$ ). Our study findings about the current smoking status was similar with the Global Adult Tobacco Survey: Bangladesh by World Health Organization (Organization, 2009) and lower than the study conducted in Lebanon (30\%) (Yahia et al., 2008). A previous study conducted among 2443 students from 13 public and private schools in Greater Beirut (Tamim et al., 2007) reported that the prevalence rate of cigarette smoking was $2.5 \%$ which was very lower than our findings.

\section{Limitations}

This study was not without limitations. Firstly, it is limited by the self-reported data which might have influenced the results through respondent bias. The study was also limited by relatively small sample size and recruiting sample from only one university, so generalization of the whole country was not possible. Country 
representative studies are recommended to overcome such limitations. However, baseline information about weight status and eating habits among a sample of university students were certainly obtained from the present study.

\section{Conclusions}

Despite the low prevalence of overweight and obesity in the studied university students' sample, results indicate that university students would benefit from a nutrition and health promotion program to reduce the tendency of overweight and obesity among students and to improve students' eating habits.

\section{Conflict of interest}

None to declare.

\section{References}

Al-Isa AN, 1999. Obesity among Kuwait University students: an explorative study. J. R. Soc. Promot. Health, 119: 223-227.

Al-Qahtani MH, 2016. Dietary habits of Saudi medical students at University of Dammam. International Journal of Health Sciences, 10: 353.

Al-Rethaiaa AS, AEA Fahmy and NM Al-Shwaiyat, 2010. Obesity and eating habits among college students in Saudi Arabia: a cross sectional study. Nutr. J., 9: 39.

Arroyo IM, AM Rocandio Pablo, L Ansotegui Alday, E Pascual Apalauza, I Salces Beti and E Rebato Ochoa, 2006. Diet quality, overweight and obesity in university students. Nutrición Hospitalaria, 21: 673-679.

Bertsias G, I Mammas, M Linardakis and A Kafatos, 2003. Overweight and obesity in relation to cardiovascular disease risk factors among medical students in Crete, Greece. BMC Public Health, 3: 3.

Davy SR, BA Benes and JA Driskell, 2006. Sex differences in dieting trends, eating habits, and nutrition beliefs of a group of midwestern college students. J. Am. Diet. Assoc., 106: 1673-1677.

Field AE, L Cheung, AM Wolf, DB Herzog, SL Gortmaker and GA Colditz, 1999. Exposure to the mass media and weight concerns among girls. Pediatrics, 103: e36.

Gazibara T, DB Kisic Tepavcevic, A Popovic and T Pekmezovic, 2013. Eating habits and body-weights of students of the University of Belgrade, Serbia: A cross-sectional study. J. Health Popul. Nutr., 31: 330-333.

Genena DM and AA Salama, 2017. Obesity and eating habits among university students in Alexandria, Egypt: A cross sectional study. World J. Nutr. Health, 5: 62-68.

Glore SR, C Walker and A Chandler, 1993. Brief communication: dietary habits of first-year medical students as determined by computer software analysis of three-day food records. J. Am. Coll. Nutr., 12: 517-520.

Hu F, 2008. Obesity epidemiology. Oxford University Press.

Lee RD and DC Nieman, 1993. 'Nutritional assessment. Brown \& Benchmark'. Oxford, UK.

Musaiger AO, OL_Lloyd__SM_Al-Neyadi and_AB_Bener, 2003. Lifestyle factors associated with obesity among male university students in the United Arab Emirates. Nutrition \& Food Science, 33: 145-147.

Organization WH, 2009. Global adult tobacco survey: Bangladesh Report 2009. WHO Regional Office for South-East Asia.

Peltzer K, S Pengpid, TA Samuels, NK Özcan, C Mantilla, OH Rahamefy, ML Wong and A Gasparishvili, 2014. Prevalence of overweight/obesity and its associated factors among university students from 22 countries. Int. J. Environ. Res. Public Health, 11: 7425-7441.

Pengpid S and K Peltzer, 2014. Prevalence of overweight/obesity and central obesity and its associated factors among a sample of university students in India. Obes. Res. Clin. Pract., 8: e558-e570.

Popkin BM, LS Adair and SW Ng, 2012. Global nutrition transition and the pandemic of obesity in developing countries. Nutr. Rev., 70: 3-21.

Sakamaki R, R Amamoto, Y Mochida, N Shinfuku and K Toyama, 2005. A comparative study of food habits and body shape perception of university students in Japan and Korea. Nutr. J., 4: 31.

Tamim H, B Al-Sahab, G Akkary, M Ghanem, N Tamim, Z El Roueiheb, M Kanj and R Afifi, 2007. Cigarette and nargileh smoking practices among school students in Beirut, Lebanon. Am. J. Health Behav., 31: 56-63.

Taylor CB, T Sharpe, C Shisslak, S Bryson, LS Estes, N Gray, KM McKnight, M Crago, HC Kraemer and JD Killen, 1998. Factors associated with weight concerns in adolescent girls. Int. J. Eat. Disord., 24: 31-42.

Wardle J, AM Haase, A Steptoe, M Nillapun, K Jonwutiwes and F Bellisle, 2004. Gender differences in food choice: the contribution of health beliefs and dieting. Ann. Behav. Med., 27: 107-116.

N Yahia, A Achkar, A Abdallah and S Rizk, 2008. Eating habits and obesity among Lebanese university students. Nutr. J., 7: 32. 